\title{
Los antecedentes a la colegiación obligatoria de las matronas en Madrid
}

\section{The background to the mandatory professional assotiation of midwives in Madrid}

\section{O plano de fundo para a concessão de licenças obrigatórias de parteiras em Madrid}

\author{
Ma Dolores Ruiz-Berdún
}

Matrona, Diplomada en Estudios Avanzados en Historia de la Ciencia por la Universidad de Alcalá, profesora de la Unidad Docente de Matronas de Madrid, profesora colaboradora de la EUE Cruz Roja de Madrid

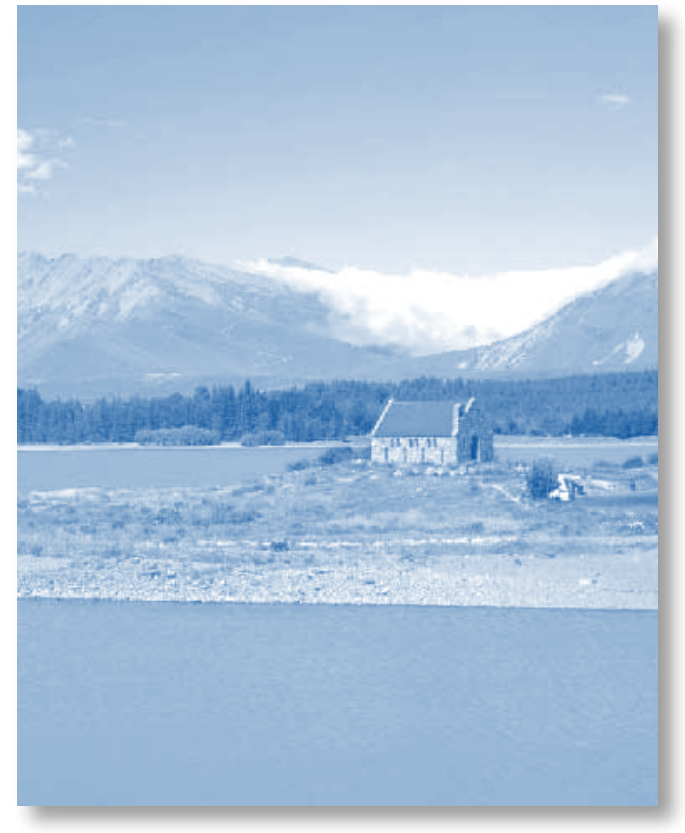

\section{ABSTRACT}

This work aims to clarify definitively, the dates of constitution and the purposes of various corporate partnerships that arose prior to the mandatory professional association in 1930 and assess the so hackneyed hypothesis that, prior to that date, did not exist between the midwives collective interest by the professional association.

Keywords: Midwives, corporatism, mandatory professional association.

\section{RESUMO}

Este trabalho tem como objetivo esclarecer definitivamente, as datas da Constituição e efeitos de diversas parcerias corporativas que surgiram antes do licenciamento compulsório do ano 1930 e avaliar a hipótese, tão banal que, antes dessa data, nao existía entre o colectivo de parteiras interesse pela associação profissional.

Palavras-chave: Parteiras, corporativismo, licenças obrigatórias.

\section{RESUMEN}

El presente trabajo pretende aclarar, de manera definitiva, las fechas de constitución y los fines de las diversas asociaciones corporativas que surgieron con anterioridad a la colegiación obligatoria del año 1930 y valorar la hipótesis, tan manida, de que, antes de esa fecha, no existía entre el colectivo matronal interés por la asociación profesional.

Palabras clave: Matronas, corporativismo, colegiación obligatoria.

\section{INTRODUCCIÓN}

En 1930 se aprobó por Real Orden de 7 de mayo la colegiación obligatoria de las matronas [1]. Nuestro objetivo con la presente 
investigación ha sido averiguar qué tipo de organizaciones corporativas existieron entre las matronas madrileñas anteriores a la colegiación obligatoria.

En un artículo publicado en 1899 en El Eco de las Matronas denominado «Los males que afligen a la clase de Matronas y su tratamiento", su autor, José Esbert y Roca (Esbert, 1899a y 1899b) decía refiriéndose al asociacionismo del colectivo de matronas: "Las que mangonean el gremio, procuran prescindir de la generalidad de las demás que pudieran desquiciar sus planes. La inmensa mayoría de las otras, llevadas de inconcebible apatía, ni procuran reunirse, ni aunar fuerzas». Queríamos comprobar si esta argumentación tenía fundamento o si por el contrario formaba parte de la campaña de desprestigio que tuvieron que sufrir las matronas por parte de personas que invadieron su campo competencial.

Aunque las matronas se unieron de manera esporádica en determinados momentos con diversos fines reivindicativos [2], no parece que llegaran a establecerse grupos organizados hasta finales del siglo XIX. También hubo matronas pertenecientes a grupos sanitarios multidisciplinares, como el caso de Juana Idígoras, que en junio de 1893 fue elegida síndico por el Gremio de cirujanos de tercera, matronas y comadrones que no sean médicos [3].

Algunos autores han señalado el retardo en la constitución de organizaciones corporativas formadas por matronas con respecto al colectivo de practicantes (Siles, 1999). Sin embargo, en el caso de Madrid esto no fue exactamente así. Mientras la primera asociación corporativa de practicantes exclusivamente madrileña [4], el Colegio de Practicantes de Madrid, se registraba en 1905, diez años antes había surgido el Colegio de Profesoras Titulares de Partos de Madrid [5]. Este último, no obstante debemos decir que, aunque ganó en precoci- dad no lo hizo en longevidad, ya que tuvo una existencia efímera, pues tan solo estuvo activo entre 1895 y 1896. La otra organización corporativa que vamos a considerar en el presente artículo es el Colegio de Matronas de Madrid y su provincia, que inició su andadura en 1922.

\section{EL COLEGIO DE PROFESORAS TITU- LARES DE PARTOS DE MADRID}

La constitución del Colegio de Profesoras Titulares de Partos de Madrid, se produjo en una reunión mantenida en el domicilio de la matrona Inés Echavarría, organizándose la primera Junta Directiva que quedó formada como sigue [6]:

- Presidenta: Dorotea Porqueras.

- Vicepresidenta: Petronila Pérez.

- Secretaria: María Casellas.

- Vicesecretaria: Dolores Petisme.

- Vocales: Rosa Figuerola, Carmen Pando, Inés Echavarría María Iribarren y Rosalía Solana.

La mayoría de estas matronas estaban tituladas por la Universidad Central de Madrid, siendo la más veterana de ellas Petronila Pérez, cuyo título fue registrado en 1852 y la más novata Dolores Petisme que se acababa de titular en 1895 [7].

El Colegio de Profesoras Titulares de Partos de Madrid aparece registrado con el número de orden 789 (tablas 1 y 2), declarándose como una asociación de tipo "cooperativo". La fecha de su presentación fue el 12 de julio de 1895, y su domicilio social inicial estaba en la calle San Roque 12 y 14, que era a la vez el domicilio de su presidenta Dorotea Porqueras (imagen 1) [8]. Adjuntaron como documentación dos copias de los Estatutos y una del Reglamento del Colegio. Posteriormente, en octubre de 1895, se modificó la Junta Directiva, añadiéndose otros miembros y sus estatutos fueron reformados el 30 de noviembre de ese 


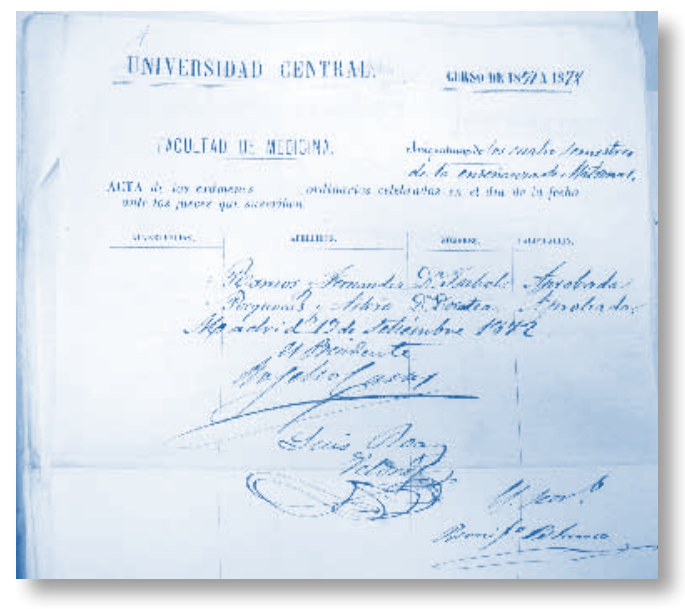

Imagen 1: Examen de los cuatro semestres de la enseñanza de matronas de Dorotea Porqueras.

mismo año, cambiando su domicilio social a la calle Corredera Alta de San Pablo número 4, $1^{\circ}$ y $2^{\circ}$, que era además el domicilio de la matrona Filiberta García [9].

Su finalidad era defender los intereses del colectivo, para lo cual desarrollaron diversas actividades entre las que se encontraban darse a conocer en diferentes ámbitos. Con este fin, mantuvieron una reunión en septiembre de 1895 con el presidente de la Diputación provincial, que por entonces era Eugenio Cemboraín España [10]. Pero tal vez su acción más significativa fue la reunión mantenida en enero de 1896 con el ministro de Hacienda, con el objetivo de reclamar una disminución en la tarifa de la contribución industrial que consideraban muy elevada para sus modestos ingresos y que en 1895 ascendían a la cantidad anual de 130,34 pesetas [11][12]. El Colegio de Profesoras Titulares de Partos de Madrid fue dado de baja del registro de asociaciones por no presentar documentos ni declarar domicilio social.

\section{EL COLEGIO DE MATRONAS DE} MADRID Y SU PROVINCIA

El Colegio de Matronas de Madrid y su provincia se constituyó en 1922. Concepción
Marín y Petronila Lahoz, como miembros fundadores del mismo, presentaron el reglamento al Gobernador Civil de Madrid el 5 de diciembre de 1922, siendo aprobado por éste cinco días más tarde (imagen 2). Su inscripción se produjo con el número de orden 3784, figurando su primer domicilio social en la calle del Barco $\mathrm{n}^{\circ} 15,1^{\circ}$, y el siguiente en la calle Juanelo $\mathrm{n}^{\circ} 13$ y 15 [13].

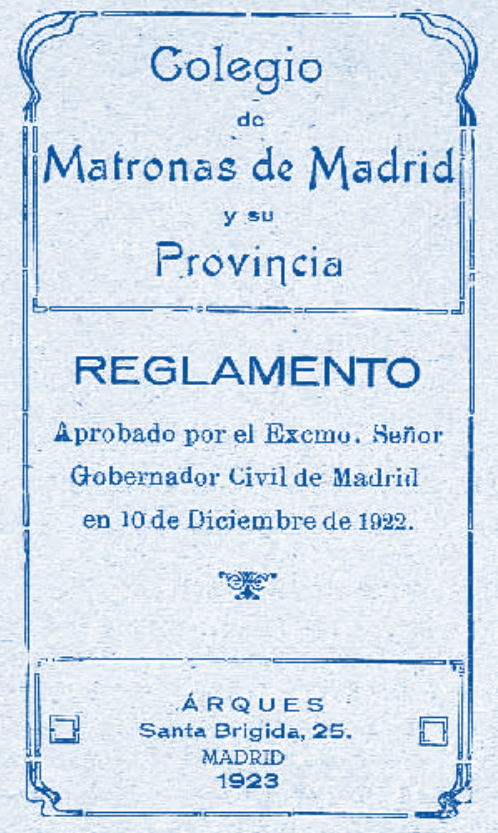

Imagen 2: Reglamento del Colegio de Matronas de Madrid y su provincia.

Al reformar sus estatutos en enero de 1927, se incluyó un cambio de denominación según la cual el Colegio de Matronas de Madrid y su provincia pasó a llamarse Unión de Matronas de Madrid y su provincia, sin embargo en la prensa madrileña de la época siguieron utilizándose ambas denominaciones indistintamente, e incluso una tercera, la Unión Matronal de Madrid. También se nombró una nueva Junta directiva, que quedó formada por las siguientes matronas [14]: 
- Presidenta: Concepción Marín.

- Vicepresidenta: Petronila Lahoz.

- Secretaria: María Santamaría.

- Vicesecretaria: Magdalena Nevado.

- Tesorera: Josefina Piñeiro.

- Contadora: África Biencinto.

- Revisoras de cuentas: Teresa Sancho, Ramona Fernández.

- Vocales: Rosa Mora, Estefanía Raso, Paz Íscar, María Iglesias, Inés García.

Buscando hacer realidad el objetivo recogido en el artículo primero del Reglamento del Colegio, relativo a "contribuir a que las Matronas alcanzasen el mayor grado de mejoramiento, progreso y cultura», la Unión de Matronas de Madrid y su provincia organizó el «Primer Congreso Nacional del Matronas Españolas». El congreso se desarrolló entre los días 16 a 20 de mayo de 1929, en la Real Academia de Medicina presentándose entre otras las ponencias siguientes [15]:

- Ventajas morales y materiales del establecimiento de la colegiación obligatoria, por Concepción Marín.

- Prescripción de medicamentos en casos urgentes por Clara Soria y Ramona Marín, ponentes procedentes de Barcelona.

- La protección de la infancia en España por Pilar Pérez.

El Congreso se clausuró el día 20 de mayo $\mathrm{y}$ fue presidido por el director general de Sanidad, Antonio Horcada Mateos. La vicesecretaria del la Unión de Matronas de Madrid, Magdalena Nevado, leyó las conclusiones del Congreso, que se habían resumido en un conjunto de peticiones:

- Instituir la hoja de inscripción del recién nacido.

- Definir claramente las carreras y competencias de las matronas, practicantes y enfermeras.
- Considerar a la matrona como el único personal auxiliar en el parto.

- Posibilidad de prescripción por parte de la matrona de los medicamentos mínimos exigidos en el parto.

- Exigencia de cumplimiento de la creación de plazas en la Beneficencia Municipal.

- Establecer la colegiación obligatoria.

- Derogación del artículo octavo del Real Decreto de 30 de agosto de 1928, referente a que aquellas que no quisieran obtener la titulación oficial, tras cursar dos años de estudios teóricos y prácticos, tuviesen la posibilidad de obtener un certificado de estudios, sin validez oficial, que las habilitase exclusivamente para la asistencia caritativa a parturientas que fuesen menesterosas, o de su propia familia.

El Director General de Sanidad opinó que algunas de estas conclusiones no eran prácticas, pero apoyó la propuesta de colegiación obligatoria. Las matronas consideraban la colegiación obligatoria como una estrategia para luchar contra el intrusismo proveniente, ya de gente sin formación, ya de otros profesionales sanitarios. Recogiendo el sentir del colectivo, la presidenta y la secretaria de la Federación Nacional de Matronas solicitaron el establecimiento de la colegiación obligatoria al Ministerio de Sanidad, que se haría realidad unos meses más tarde con la Real Orden de 7 de mayo de 1930.

Mientras tanto, continuando con el objetivo de mejorar el nivel científico de sus asociadas, a finales de noviembre de 1929, la Unión de Matronas de Madrid y su provincia publicó su primer boletín al que se denominó Unión Matronal nombrando como directora del periódico a la matrona y practicante Pilar Pérez Ramos (imagen 3) [16].

El 7 de junio de 1930, las matronas de Madrid celebraron una Junta general en el domicilio de Empleados y Obreros del Ayuntamiento, 


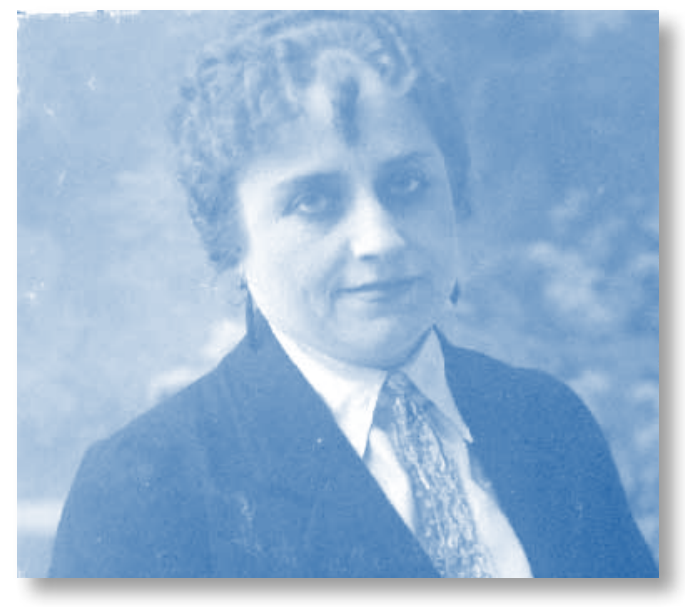

Imagen 3: Pilar Pérez Ramos, directora del boletín Unión Matronal.

que estaba localizado en la calle Santa Clara número 4, con el fin de constituirse en el Colegio Oficial de Matronas de Madrid, y así cumplir la Real Orden de 7 de mayo de 1930 [17]. Este quedó oficialmente constituido el 7 de agosto de 1930 en un solemne acto celebrado en el salón de actos del Colegio de Médicos de Madrid [18]. Desde este momento surgió una nueva etapa en el asociacionismo de las matronas madrileñas (imagen 4).

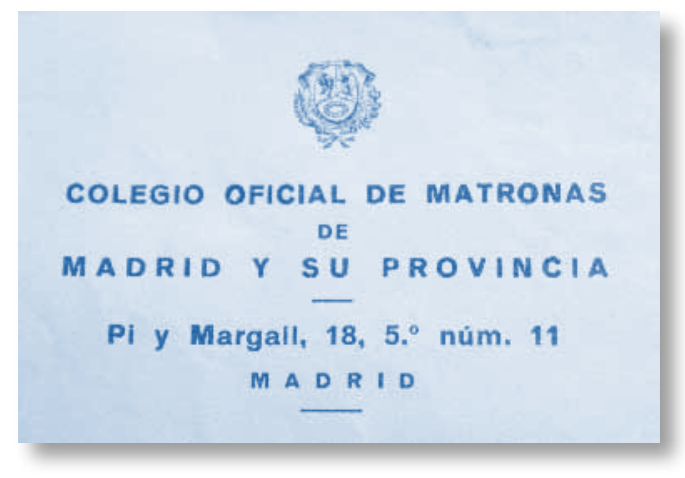

Imagen 4. Membrete del Colegio Oficial de Matronas de Madrid en 1932.

Una vez creado el Colegio Oficial de Matronas de Madrid, la Unión de Matronas decidió disolverse, pasando su capital a la creación de un Montepío o mutua para sus antiguas asociadas. Para redactar el proyecto de reglamento de dicha mutua, se nombró una comisión formada por María Ruiz, Luisa Veira, Isabel de Luis y Pilar Pérez Ramos. Las antiguas socias de la Unión de Matronas de Madrid y su provincia que estuviesen al corriente de pago de sus recibos, pasarían de manera automática a pertenecer a la nueva mutualidad; a aquellas que tuvieran recibos pendientes de pago se les dio un plazo de un mes para hacerlos efectivos, o de lo contrario, en caso de querer pertenecer a la nueva organización, deberían pagar la cuota de entrada de 15 pesetas, cantidad que se les pedía a las matronas de nuevo ingreso [19]. De esta manera se creó la Mutual de Matronas de Madrid el 31 de marzo de 1931, permaneciendo activa hasta el 31 de marzo de 1941, fecha en que fue disuelta.

\section{CONCLUSIONES}

Como hemos podido comprobar, las matronas establecieron grupos corporativos para la defensa de sus intereses antes de que se estableciera la colegiación obligatoria. No solo eso, fueron ellas mismas las que solicitaron esa colegiación obligatoria como medio de luchar contra el intrusismo. También fueron pioneras en intentar ampliar sus competencias, intentando conseguir algo que aun no se ha logrado hoy día, como es la prescripción enfermera.

\section{NOTAS}

[1]- Gaceta de Madrid, 09/05/1930.

[2]- En la tesis que estamos a punto de presentar se recogen algunas de estas reivindicaciones.

[3]- El Gremio de cirujanos de tercera, matronas y comadrones que no sean médicos, se creó en base a la organización de la contribución industrial, o impuestos que debían pagar los profesionales. Las matronas estaban comprendidas entre las profesiones de orden civil. La elección de Juana Idígoras como síndico aparece en la prensa de la época: 
«Los nuevos síndicos», La Iberia, 17/06/1893, pág. 1.

[4]- El primer grupo corporativo de practicantes que aparece en los libros de registro de asociaciones es la Asociación General de Practicantes de España, que surge en 1903.

[5]- Las tablas 1 y 2 han sido elaboradas recogiendo las organizaciones corporativas de matronas y practicantes anotadas en los libros de registro de asociaciones por orden cronológico de Inscripción hasta el 18 de julio de 1936, signaturas del Archivo General de la Administración, signaturas (08)30 36/3104, (08)30 36/3105, (08)30 36/3106, (08)30 36/3107, (08)30 36/3108, (08)30 36/3109, (08)30 36/3110, (08)30 36/3111, (08)30 36/3112, (08)30 36/3113, (08)30 36/3114, (08)30 36/3115, (08)30 36/3116, (08)30 36/3117 y (08)30 36/3118.

[6]- «Noticias», El País, 01/07/1795, pág. 3.

[7]- Libro de asientos de las reválidas de Cirujano, Sangrador y Matrona, desde $1^{\circ}$ de octubre de 1851 , en que principia el curso de 1851 á 1852 que recoge dichas reválidas entre los años 1851 y 1856 Archivo General de la Universidad Complutense de Madrid AH-0328 y Libros de registro de títulos, Archivo General de la Administración, (05) 8 Libro 105 Top. 16/64.40-64.409.

[8]- Expediente de alumna de la Universidad Central de Madrid, Archivo Histórico Nacional, fondo Universidades, leg. 1638, exp. 1.

[9]- El Imparcial, 01/05/1890, pág. 4.

[10]- El Imparcial, 06/09/1895, pág. 3

[11] La Correspondencia de España, 31/01/1896, pág.2.

[12]- Tarifa $4^{\text {a }}$ de la contribución industrial 1894-95, Archivo General de la Administración, (01)15.3 Libro 9321 Top. 11/22.506-25.105.

[13]- Archivo General de la Administración, (08)30 $36 / 3111$.

[14]- «Unión de Matronas de Madrid», La libertad, 27/01/1927, pág. 6 .

[15]- «Un congreso de matronas españolas», La Voz, 11/05/1929, pág. 4.

[16]- «Boletín del Colegio de Matronas», El Heraldo de Madrid, 27/11/1929, pág. 2.

[17]- «Colegio de matronas», La Libertad, 06/06/1930, pág. 9.
[18]- «El Colegio oficial de Matronas de Madrid», Federación Sanitaria Madrileña, septiembre de 1930, págs. 35-36. [19]- «Una mutua y una disolución», Federación Sanitaria Madrileña, diciembre de 1930, pág. 40.

\section{BIBLIOGRAFÍA}

- Barreiro Pereira, P. y Bermejo, J.M. (2009) El Colegio de Enfermería de Madrid. Cien años de Historia. Madrid

- Esbert y Roca, J. (1899) Los males que afligen a la clase de Matronas y su tratamiento. El Eco de Las Matronas, Dentistas, Callistas y Practicantes de Cirugía, 7, 80-84.

- Esbert y Roca, J. (1899) Los males que afligen a la clase de Matronas y su tratamiento. El Eco de Las Matronas, Dentistas, Callistas y Practicantes de Cirugía, 8, 95-99.

- Estatuto de los Colegios Oficiales de Matronas, disponible en http://www.boe.es/datos/pdfs/BOE/1930/129/ A00913-00915.pdf

-Montesinos Vicente, F. (2011) Organización corporativa y autogobierno En: Practicantes, Matronas y Cirujanos Dentistas en la España Contemporánea (1855-1932), Universitat de Girona pp. 307-402

-Reglamento del Colegio de Matronas de Madrid y su provincia (1922) disponible en http://www.bibliotecavirtualmadrid.org/i18n/consulta/registro.cmd?id=30

-Siles González, J. (1999) Corporativismo en España. En Historia de la Enfermería, Aguaclara, Alicante pp. 300311 


\begin{tabular}{|c|c|c|c|c|c|}
\hline Denominación & $\begin{array}{l}\text { Evolución y } \\
\text { denominaciones } \\
\text { posteriores }\end{array}$ & $\begin{array}{l}\mathrm{N}^{\circ} \text { de } \\
\text { Registro }\end{array}$ & $\begin{array}{l}\text { Fechas de } \\
\text { Presentación y de } \\
\text { constitución }\end{array}$ & $\begin{array}{l}\text { Primer } \\
\text { presidente }\end{array}$ & $\begin{array}{l}\text { Primer domicilio } \\
\text { social }\end{array}$ \\
\hline $\begin{array}{l}\text { Colegio de Profesoras } \\
\text { Titulares en partos de } \\
\text { Madrid }\end{array}$ & Dada de baja & 789 & $\begin{array}{l}12 / 07 / 1895 \\
21 / 11 / 1895\end{array}$ & $\mathrm{M}^{\mathrm{a}}$ Amparo Ramírez & $\begin{array}{l}\mathrm{C} / \text { San Roque } \mathrm{n}^{\circ} 12 \text { y } 14 \\
\text { entresuelo }\end{array}$ \\
\hline $\begin{array}{l}\text { Asociación General de } \\
\text { Practicantes de España }\end{array}$ & $\begin{array}{l}\text { Disuelta el } 14 \text { de junio de } \\
1904\end{array}$ & 1349 & $\begin{array}{l}01 / 02 / 1903 \\
14 / 021903\end{array}$ & Juan José Fernández & $\mathrm{C} / \mathrm{Abada} \mathrm{n}^{\circ} 27$ tienda \\
\hline $\begin{array}{l}\text { Colegio de Practicantes } \\
\text { de Madrid }\end{array}$ & $\begin{array}{l}\text { Colegio de Auxiliares de } \\
\text { Medicina y Cirugia. } \\
\text { Después: Colegio de } \\
\text { Auxiliares de Medicina y } \\
\text { Cirugía de Madrid. }\end{array}$ & 1549 & $\begin{array}{l}15 / 03 / 1905 \\
31 / 03 / 1905\end{array}$ & Carlos Chies & $\mathrm{C} /$ Esperanza $\mathrm{n}^{\circ} 3$ principal \\
\hline $\begin{array}{l}\text { Asociación española de } \\
\text { auxiliares de Medicina }\end{array}$ & Consta como dada de baja & 3318 & $\begin{array}{l}18 / 08 / 1918 \\
30 / 08 / 1918\end{array}$ & Luis López & $\mathrm{C} /$ Mayor $\mathrm{n}^{\circ} 1$ \\
\hline $\begin{array}{l}\text { Sindicato de practicantes } \\
\text { y matronas del distrito de } \\
\text { Getafe }\end{array}$ & $\begin{array}{l}\text { Disuelto el } 19 \text { de junio de } \\
1926\end{array}$ & 3595 & $\begin{array}{l}15 / 06 / 1920 \\
25 / 07 / 1920\end{array}$ & Agapito Ocejo & Leganés \\
\hline $\begin{array}{l}\text { Colegio de Matronas de } \\
\text { Madrid y su provincia }\end{array}$ & $\begin{array}{l}\text { Unión de Matronas de } \\
\text { Madrid y su provincia. Dada } \\
\text { de baja }\end{array}$ & 3784 & $\begin{array}{l}10 / 12 / 1922 \\
12 / 01 / 1923\end{array}$ & Petronila Lahoz & $\mathrm{C} / \mathrm{Barco}^{\circ} 151^{\circ}$ \\
\hline $\begin{array}{l}\text { Sindicato Católico de } \\
\text { Practicantes de Medicina } \\
\text { y Cirugía de Madrid }\end{array}$ & Consta como dado de baja & & $\begin{array}{l}07 / 04 / 1926 \\
20 / 04 / 1926\end{array}$ & Baldomero Coello & $\begin{array}{l}\text { Plaza del Marqués de } \\
\text { Comillas } n^{\circ} 7\end{array}$ \\
\hline
\end{tabular}

Tabla 1: Movimientos corporativos de matronas y practicantes en Madrid por orden de aparición en los libros de registro de asociaciones (primera parte).

\begin{tabular}{|c|c|c|c|c|c|}
\hline Denominación & $\begin{array}{l}\text { Evolución y } \\
\text { denominaciones } \\
\text { posteriores }\end{array}$ & $\begin{array}{c}\mathrm{N}^{\circ} \text { de } \\
\text { Registro }\end{array}$ & $\begin{array}{l}\text { Fechas de } \\
\text { Presentación y de } \\
\text { constitución }\end{array}$ & $\begin{array}{l}\text { Primer } \\
\text { presidente }\end{array}$ & $\begin{array}{l}\text { Primer domicilio } \\
\text { social }\end{array}$ \\
\hline $\begin{array}{l}\text { Federación Matronal } \\
\text { Española }\end{array}$ & Consta como dada de baja & 4392 & $\begin{array}{l}20 / 10 / 1926 \\
03 / 11 / 1926\end{array}$ & Ángela Zapata & $\mathrm{C} /$ Granada $\mathrm{n}^{\circ} 2$ principal izda \\
\hline $\begin{array}{l}\text { Colegio Matronal de } \\
\text { Castilla la Nueva }\end{array}$ & $\begin{array}{l}\text { Unión Matronal de Castilla } \\
\text { la Nueva }\end{array}$ & 4406 & $\begin{array}{l}20 / 11 / 1926 \\
29 / 11 / 1926\end{array}$ & Antonia Álvarez & $\mathrm{C} /$ Caridad $\mathrm{n}^{\circ} 3$ bajo \\
\hline $\begin{array}{l}\text { Federación Nacional de } \\
\text { Colegios de Practicantes }\end{array}$ & Disuelta el $21 / 05 / 1930$ & 4429 & $\begin{array}{l}20 / 01 / 1927 \\
01 / 02 / 1927\end{array}$ & Leonardo Sánchez & $\mathrm{C} /$ Reina $\mathrm{n}^{\circ} 2$ \\
\hline $\begin{array}{l}\text { Asociación de } \\
\text { Practicantes de } \\
\text { sociedades } \\
\text { benéfico-sanitarias }\end{array}$ & Consta como dada de baja & & $\begin{array}{l}21 / 03 / 1927 \\
01 / 04 / 1927\end{array}$ & Fernando Mateos & $\mathrm{C} /$ Reina $\mathrm{n}^{\circ} 2$ \\
\hline $\begin{array}{l}\text { Asociación de matronas } \\
\text { Puericultoras, alumnas } \\
\text { de la Escuela Nacional }\end{array}$ & Consta como dada de baja & 5008 & $\begin{array}{l}21 / 01 / 1930 \\
20 / 02 / 1930\end{array}$ & $\mathrm{M}^{\mathrm{a}}$ Antonia Carrillo & Paseo de Rosales $n^{\circ} 18$ \\
\hline $\begin{array}{l}\text { Federación Nacional de } \\
\text { Colegios de Practicantes } \\
\text { de España }\end{array}$ & Consta como dada de baja & 5112 & $\begin{array}{l}31 / 05 / 1930 \\
15 / 06 / 1930\end{array}$ & Balbino García & $\mathrm{C} / \mathrm{de}$ la Reina $\mathrm{n}^{\circ} 2$ \\
\hline $\begin{array}{l}\text { Asociación } \\
\text { muto-benéfica del } \\
\text { Colegio Oficial de } \\
\text { Practicantes de Madrid }\end{array}$ & $\begin{array}{l}\text { Disuelta en virtud de la OM } \\
\text { de } 14 / 04 / 1943\end{array}$ & 5207 & $\begin{array}{l}12 / 11 / 1930 \\
30 / 12 / 1930\end{array}$ & Luis López & C/ Pelayo $n^{\circ} 3$ \\
\hline
\end{tabular}

Tabla 2: Movimientos corporativos de matronas y practicantes en Madrid por orden de aparición en los libros de registro de asociaciones (segunda parte) 


\section{Cultura de las Cuidados}

\begin{tabular}{|c|c|c|c|c|c|}
\hline Denominación & $\begin{array}{l}\text { Evolución y } \\
\text { denominaciones } \\
\text { posteriores }\end{array}$ & $\begin{array}{c}\mathrm{N}^{\circ} \text { de } \\
\text { Registro }\end{array}$ & $\begin{array}{l}\text { Fechas de } \\
\text { Presentación y de } \\
\text { constitución }\end{array}$ & $\begin{array}{l}\text { Primer } \\
\text { presidente }\end{array}$ & $\begin{array}{l}\text { Primer domicilio } \\
\text { social }\end{array}$ \\
\hline $\begin{array}{l}\text { Asociación de Matronas } \\
\text { de Sociedades }\end{array}$ & $\begin{array}{l}\text { Pasa al registro de } \\
\text { asociaciones profesionales } \\
\text { el } 01 / 07 / 1933\end{array}$ & 5294 & $\begin{array}{l}13 / 04 / 1931 \\
25 / 04 / 1931\end{array}$ & $\begin{array}{l}\text { Purificación de la } \\
\text { Alcea }\end{array}$ & Avda. Pi y Margall n ${ }^{\circ} 18$ \\
\hline $\begin{array}{l}\text { Mutual de Matronas de } \\
\text { Madrid }\end{array}$ & $\begin{array}{l}\text { Disuelta el } 31 \text { de marzo de } \\
1941\end{array}$ & 5355 & $\begin{array}{l}23 / 03 / 1931 \\
02 / 06 / 1931\end{array}$ & María Ruiz & Avda. Pi y Margall $n^{\circ} 18$ \\
\hline $\begin{array}{l}\text { Agrupación de Matronas } \\
\text { de Madrid y sus } \\
\text { limitrofes. }\end{array}$ & $\begin{array}{l}\text { Pasa al registro de } \\
\text { asociaciones profesionales } \\
\text { el } 1 \text { de julio de } 1933\end{array}$ & 5394 & $\begin{array}{l}01 / 06 / 1931 \\
12 / 06 / 1931\end{array}$ & $\begin{array}{l}\text { Áurea Rubio } \\
\text { Villanueva }\end{array}$ & $\mathrm{C} /$ Piamonte $\mathrm{n}^{\circ} 2$ \\
\hline $\begin{array}{l}\text { Agrupación de } \\
\text { Practicantes de Medicina } \\
\text { y Cirugía de Madrid y su } \\
\text { provincia }\end{array}$ & $\begin{array}{l}\text { Pasa a registro de } \\
\text { asociaciones profesionales } \\
\text { el } 1 \text { de julio de } 1933\end{array}$ & 5415 & $\begin{array}{l}30 / 05 / 1931 \\
18 / 06 / 1931\end{array}$ & Ernesto Santa Cruz & $\mathrm{C} /$ Piamonte $\mathrm{n}^{\circ} 2$ \\
\hline $\begin{array}{l}\text { Asociación de auxiliares } \\
\text { sanitarios }\end{array}$ & & 5425 & & Fernando Tello & C/ Ramón de la Cruz n ${ }^{\circ} 70$ \\
\hline $\begin{array}{l}\text { Federación de Colegios } \\
\text { Oficiales de Matronas } \\
\text { Españolas }\end{array}$ & Consta como dada de baja & 5707 & $\begin{array}{l}03 / 02 / 1931 \\
02 / 12 / 1931\end{array}$ & Concepción Marín & Avda. Pi y Margall, $\mathrm{n}^{\circ} 18$ \\
\hline El Ateneo de Practicantes & $\begin{array}{l}\text { Disuelta el } 15 \text { de enero de } \\
1936\end{array}$ & 5785 & $\begin{array}{l}23 / 01 / 1932 \\
23 / 01 / 1932\end{array}$ & Eliseo Cobo & C/ Rosalía de Castro $n^{\circ} 36$ \\
\hline $\begin{array}{l}\text { Asociación de } \\
\text { Practicantes de la Cruz } \\
\text { Roja Española }\end{array}$ & Consta como dada de baja & 6255 & $\begin{array}{l}22 / 12 / 1932 \\
09 / 01 / 1933\end{array}$ & Enrique Almansa & $\begin{array}{l}\text { C/ Rosalia de Castro } \\
\mathrm{n}^{\circ} 36\end{array}$ \\
\hline
\end{tabular}

Tabla 3: Movimientos corporativos de matronas y practicantes en Madrid por orden de aparición en los libros de registro de asociaciones (tercera parte) 